\section{SOI: 1.1/TAS DOI: 10.15863/TAS International Scientific Journal Theoretical \& Applied Science}

p-ISSN: 2308-4944 (print) e-ISSN: 2409-0085 (online)

Year: $2018 \quad$ Issue: 03 Volume: 59

Published: $20.03 .2018 \quad$ http://T-Science.org
Vasila Karimbekovna Abdullaeva

Doctor of sciences in medicine,

Head of Department of psychiatry and medical psychology

Tashkent pediatric medical institute, Uzbekistan

Shuhrat Rahimovich Suleymanov

Senior lecturer of Department of psychiatry and medical psychology

Tashkent pediatric medical institute, Uzbekistan

SECTION 20. Medicine.

\title{
CHARACTER TRAITS AND COPING STRATEGIES IN TEENAGERS WITH MENTAL RETARDATION
}

Abstract: In order to identify the characteristics of teenagers with mental retardation and determine the characteristic coping strategies, 32 teenagers with mild mental retardation of 14-18 years were examined by clinical psychopathological method. The interrelationships of psychological protection mechanisms, conscious coping strategies and behavioural characteristics of teenagers with mental retardation indicate the complex impact of psychological protection on the socio-psychological adaptation of these teenagers.

Key words: teenagers, mental retardation, coping strategies

Language: English

Citation: Abdullaeva VK, Suleymanov SR (2018) CHARACTER TRAITS AND COPING STRATEGIES IN TEENAGERS WITH MENTAL RETARDATION. ISJ Theoretical \& Applied Science, 03 (59): 138-140.

Soi: http://s-o-i.org/1.1/TAS-03-59-21 Doi: crossef https://dx.doi.org/10.15863/TAS.2018.03.59.21

\section{Introduction}

The problem of development, education and upbringing of children and teenagers with mental retardation is one of the most important problems of our time. Numerous researchers have expanded the understanding of the structure of mental disorders of mentally retarded teenagers and their adaptive capabilities [6, p. 310; 9, p. 26].

From clinical and psychopathological positions, mental retardation is considered as one of the variants of dysontogenesis, in which the main manifestations are violations of cognitive activity, emotional, volitional, motivational spheres and personal immaturity.

A mentally retarded child is constantly in a situation where adverse socio-psychological factors can interact with dysfunctional biological soil [3, 390]. In order to cope with external and internal conflicts, the ability to resist mental disorganization and behavior, to be able to avoid tension, children and adolescents with mental retardation are forced to use psychological protection more intensively in their behavior.

Psychological protection mechanisms operate in the daily experience of children and adolescents, allowing them to resolve internal and external conflicts and to combat anxiety. In situations of psychological threat, they also use a variety of coping strategies. Each of the many behavioral, emotional and intellectual coping strategies of the individual can be considered not only as a conscious variant of psychological protection, but also include several such strategies [2, p. 122; 4, p. 1222].

The behavior of the mentally retarded child, as well as normal, is associated with the characterological characteristics of his personality. One of the mechanisms of adaptation of a person to changing social conditions is coping behavior, which requires special efforts from him / her and the manifestation of imperceptible personal qualities [3, p. 11].

Coping behavior strategies (coping behavior) are determined not only by the age factor, but also by the peculiarities of the child's mental (mental, personal and emotional) development. Intellectual insufficiency of varying degrees is a group of different variants of deviations in the structure of intelligence and the formation of certain aspects of the psyche that hinder the adaptive capabilities of children and adolescents. When intellectual development is disturbed, the coping behavior process fails at the stage of the "primary assessment" - a cognitive process with emotional components [8, p. 161].

Coping behavior of mentally retarded teenagers with problematic situations determines to a large extent the effectiveness of their social and psychological adaptation to changing living conditions [1, p. 2907; 5, p. 1003]. 
In the event of negative, psychotraumatic experiences, when there is a need to cope with emotional stress, a person resorts not only to conscious, but also unconscious activity of his psyche in the elimination of emotional discomfort involved unconscious mechanisms of psychological protection, allowing to balance the internal state of a person and stabilize his behavior [10, p. 516; 11, p. 80].

In this regard, it is important to study the psychological protection of mentally retarded adolescents with different types of character accentuations that determine the development of protective behavior options that lead to adaptation or disadaptation of such adolescents. This will improve the processes of their medical and psychological support and socio-psychological adaptation.

The aim of the study was to identify the characteristics of teenagers with mental retardation and to determine the characteristic coping strategies.

\section{Material and methods:}

The study surveyed 32 of a teenager with mild mental retardation aged between 14-18. Were used clinical-psychopathological method, patoharakterologik diagnostic questionnaire (PDO) for adolescents (A.E. Lichko, N.I. Ivanov, 1994); a questionnaire of coping strategies of school-age SCSI, adapted N.A.Sirota and V.M.Yaltonskiy (1994).

\section{Results and discussion:}

The study revealed 15 types of character accentuations, with the most common epileptoid $(42.4 \%)$, epileptoid-hysteroid $(18.2 \%)$, hysteroid (7.6\%) and schizoid-epileptoid (7.6\%). In the study of character types we studied some behavioral characteristics of adolescents. Thus, the reaction of emancipation, the possibility of forming psychopathies, the risk of suicide attempts were revealed, and their indicators of the risks of social disadaptation and early sexual life in adolescent girls were increased.

It can be assumed that, performing an adaptive function in the inner world of a teenager with mental retardation, accentuated traits at the same time often cause his disadaptation to the people around him, the environment and living conditions. They are due to the innate properties of the nervous system, intellectual underdevelopment and peculiarities of the emotional and volitional sphere, as well as social factors and, first of all, disadvantages of education.

Found that mentally retarded adolescents with hyperthymic, sensitive, epileptoid, schizoid-hysteroid accentuations of character represent an increased risk for the occurrence of behavioral disturbances.

The study of coping strategies used by adolescents with mental retardation in unpleasant situations showed that the most significant tense situations for adolescents with mental retardation are: "there were such situations, but now I do not remember" (25.8\%), "quarrel with relatives" $(17.7 \%)$, "quarrel with a friend" $(11.3 \%)$, "fear of physical threat from" $(11.3 \%)$.

Teenagers with mental retardation in tense situations resort to the use of coping "entertainment and physical relaxation", i.e. use behavioral ways of coping with the conflict.

It should be noted that the implementation of the problem-solving strategy requires sufficiently developed thinking. In adolescents with mental retardation, this coping takes 3rd place for use. Behavioral strategy "Privacy, avoidance" is actively used in the study group. It is established that groups of kopings relating to "aggression" and "expression of emotions" are expressed in the least degree. In addition, the greatest number of coping strategies was revealed in mentally retarded adolescents with labile, sensitively schizoid types of character accentuations.

The analysis of the study of the effectiveness of strategies showed that mentally retarded adolescents most of all help to cope with the anxiety of "entertainment and physical relaxation" (19.4\%), "search for social support" (17\%).

A lower percentage of the effectiveness of the "seeking social support" strategy in the pilot group should be noted. Perhaps this is due to the fact that adolescents with mental retardation can not always count on the help of people around them, especially from the family. This feature is noted in the list of causes of unpleasant situations where "quarrel with relatives" ranks first among adolescents with mental retardation.

In the study of the strategy of protective behavior, characteristic of representatives of different types of accentuations of character, it is shown that in mentally retarded adolescents with hyperthymic, schizoid, epileptoid, hysteroid, epileptoid-hysteroid accentuations protective behavior is aimed at "entertainment and physical relaxation".

For mentally retarded adolescents with unstable, sensitive, sensitive-schizoid, labilesensitive, labile-hysteroid accents characterized by "relief of the soul, problem-solving planning" in difficult situations.

Labile adolescents with mental retardation use the strategy "search of social support" and "entertainment and physical activity", asthenoneurotic teenagers - strategies "relief of the soul, the planning problem-solving" and "search of social support", schizoid adolescents strategy "solitude avoidance", labile-cycloid - "search of social support", schizoid-hysteroid strategies "expression of emotions", "search of social support", "entertainment and physical activity".

Coping behavior of adolescents with mental retardation was characterized by action in a difficult 
situation according to the pattern using from one to three coping strategies, while adolescents with normative development have a wide range of behavioral strategies. The primitive strategies of coping behavior of adolescents with mental retardation are partly due to the lack of flexibility of their thinking, reduced ability to learn, delayed accumulation of life experience.

\section{Conclusions:}

Thus, the accentuation of character, lack of intelligence, lack of family education of mentally retarded adolescents often cause violations of their social adaptation in the environment. Among the various character accentuations in adolescents with mental retardation, epileptoid type of character accentuation is statistically more common. Different types of character accentuations in adolescents with mental retardation significantly affect the structure of psychological protection.

The greatest manifestation of the protection mechanisms identified in adolescents with mental retardation with the sensitive-schizoid, sensitive, hyperthymic, asthenic-neurotic character accentuation, and coping strategies - labile, sensitiveschizoid, schizoid-epileptic of character accentuations.

For accentuated adolescents with mental retardation, the most effective coping strategies are "entertainment and physical relaxation" and "search for social support". The interrelationships of psychological protection mechanisms, conscious coping strategies and behavioural characteristics of adolescents with mental retardation indicate the complex impact of psychological protection on the socio-psychological adaptation of these adolescents.

\section{References:}

1. Blair CT (2003). The use of religious coping and perceptions of family functioning of parents who have a child with a developmental disability. Dissertation Abstracts International: Section B: The Sciences and Engineering. 64, p. 2907.

2. Bodrov VA (2006) Problema preodoleniya stressa: «Coping Stress» I teoreticheskie podhodi k ego izucheniyu // Psihologicheskiy jurnal, T.27, № 1, pp. 122-133.

3. Farheen A, Dixit S, Bansal SB, Yesikar V (2008) Coping strategies in families with mentally retarded children. Indian J Pract Doct., Vol.5, pp. 11-12.

4. Gallagher S, Whiteley J (2012). The association between stress and physical health problems in parents caring for children with intellectual disabilities is moderated by children's challenging behaviors. Journal of Health Psychology, Vol. 18(9), pp. 1220-1231.

5. Glidden LM., Natcher AL (2009). Coping strategy use, personality, and adjustment of parents rearing children with developmental delays. Journal of Intellectual Disability Research, Vol. 53, pp. 998-1013.
6. Glidden LM (2012). Family well-being and children with intellectual disability. The Oxford Handbook of Intellectual Disability and Development, pp. 303-317.

7. Grant G, Whittell B (2000). Differentiated coping strategies in families with children and adults with intellectual disabilities: The relevance of gender, family composition and the life span. Journal of Applied Research in Intellectual Disabilities, Vol. 13, pp. 256-275.

8. Heiman T (2002). Parents of children with disabilities: resilience, coping and future expectations. Journal of Developmental and Physical Disabilities, Vol.14, pp.159-171.

9. Isaev DN (2003) Umstvennaya otstalost u detey I podrostkov, $\mathrm{SPb}$.;Rech, $391 \mathrm{p}$.

10. Sharifi M, Kaveh M (2012) The Effect of Teaching Coping Strategies on the Mental Health of 13-17 Male Adolescents Living in Boarding Houses of Tehran // Procedia-Social and Behavioral Sciences, Vol.84, pp. 514-519.

11. Taanila A., Syrjala L, Kokkonen J, Jarvelin MR (2012). Coping of parents with physically and/or intellectually disabled children. Child: Care, Health and Development, Vol. 28, pp. 73-86. 